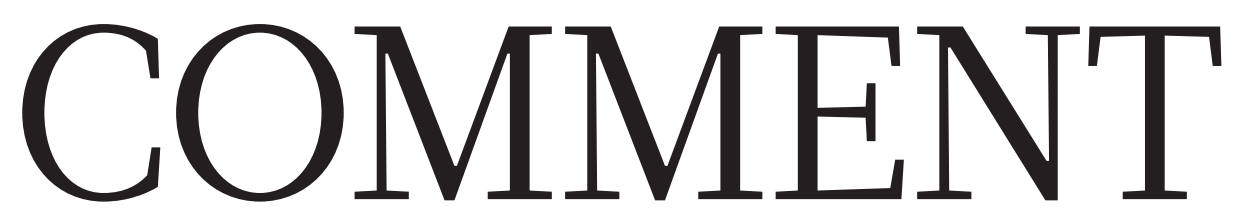

EUROPE Experts' demands in times of trial: love, money, trust $\mathbf{p . 4 8 1}$
NEUROSCIENCE The mysterious hallucinogen mescaline: a history $\mathbf{p . 4 8 5}$
CONSERVATION Rarest great ape or a new dam - Indonesia faces stark choice $\mathbf{p . 4 8 7}$
OBITUARY Paul Greengard, Nobel laureate who traced brain signals, remembered p.488

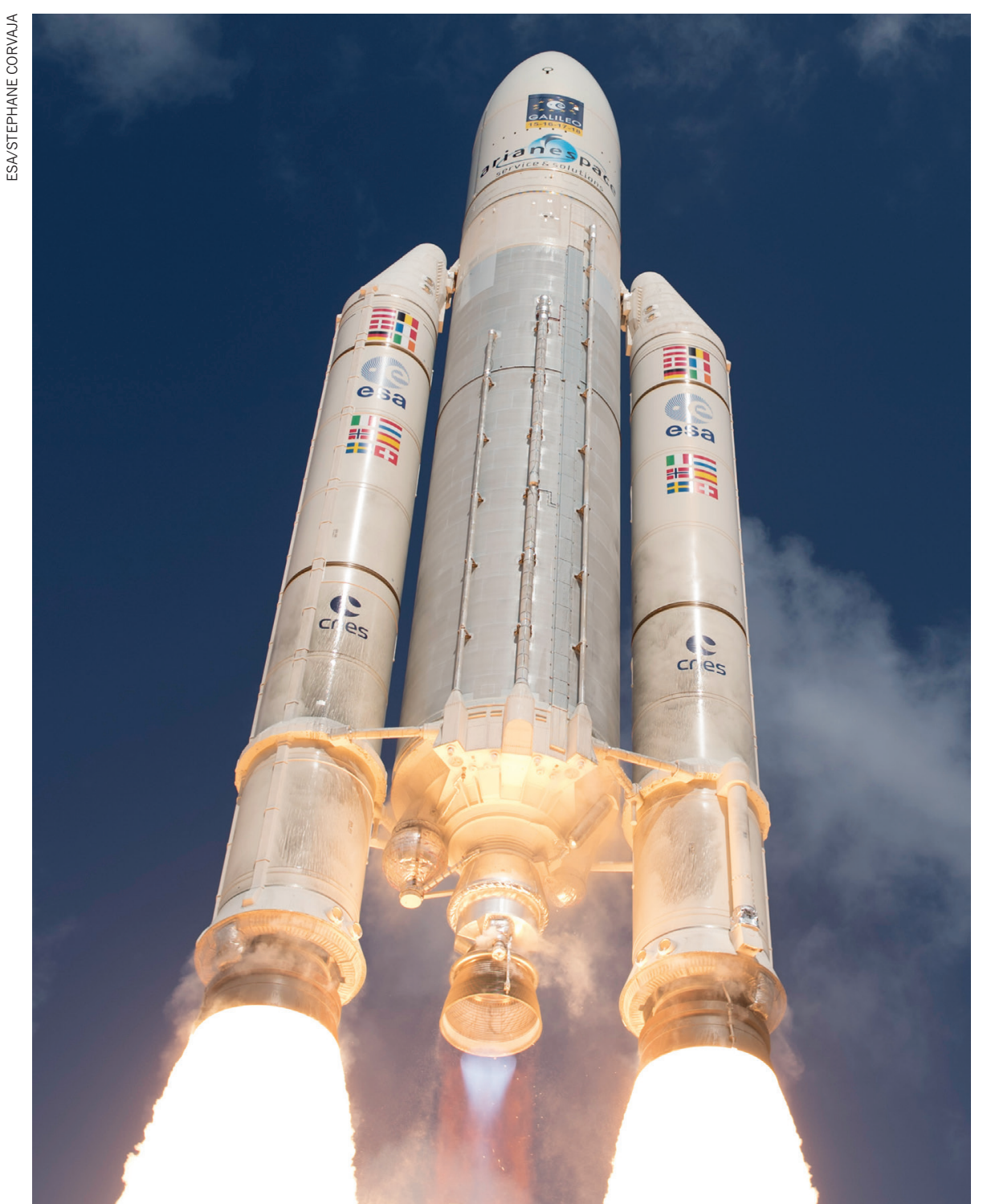

A rocket ferries four of the European Union's Galileo navigation satellites into space.

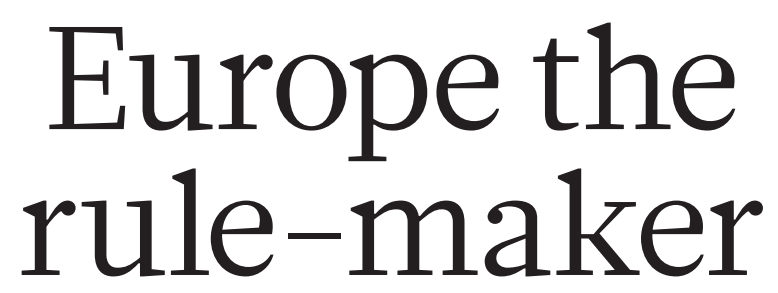

Proactive, cosmopolitan and open, the European Union is filling a leadership void on the global stage, argue James Wilsdon and Sarah de Rijcke.
T ast month, in their final session before elections, a thumping majority of Imembers of the European Parliament approved the legislative package for the European Union's next programme for research and innovation, Horizon Europe. Arguments will rage for another six months about the size of its budget - now pencilled in at $€ 94$ billion (US\$106 billion) by the European Commission and member states. Such ritual debates are important, but they can obscure a greater achievement.

Over the past decade, there has been a palpable shift in the scale of Europe's influence over the governance and direction of global research. And its ambition doesn't stop there: the EU also wants to lead the world's approach to a host of policy agendas informed by science, including climate change, chemicals regulation and data protection.

A more proactive Europe is filling a void in international scientific leadership. This has been created by the United States' retreat from multilateralism under President Donald Trump, which affects science, as many other spheres. China is struggling to switch its emphasis from research quantity to addressing thornier issues of scientific quality, ethics and integrity. And the United Kingdom's exit from Europe will blight its political and research systems for the next decade.

Since their introduction in the early 1980s, the European framework programmes for research and innovation have steadily grown in budget and complexity. Their focus has also evolved: from supporting research and development (R\&D) linked to a handful of industrial sectors, to promoting research coordination and cohesion, and strengthening capacity, mobility and infrastructure across the EU member states ${ }^{1}$.

Today, the most striking feature of the programmes is the extent to which they are designing and embedding the operating principles for research across Europe and, by default, the wider world. These principles range from open science and open data to the alignment of R\&D with societal priorities and global goals. To achieve this with a budget that amounts to only about $10 \%$ of the total public investment in R\&D across EU member states is even more remarkable.

As Europe's scientific community 
$>$ readies itself for a new parliament, a new commission and a new framework programme, there are uncertainties ahead. But the bloc is poised to take a greater lead in shaping research that is cosmopolitan, open and mission-driven. If the EU can hold its nerve, its model of science policy and governance will be more influential than ever on the international stage in the decade to come.

\section{STRUCTURED TO LEAD}

Several factors underpin this shift. In part, it is the product of efforts to refocus the EU's role in the aftermath of the global financial crash. Research and innovation "have come to the fore of the EU's identity as a problemsolver", argues science-policy specialist Mats Benner at Lund University in Sweden ${ }^{2}$. They are tools of crisis management during a period of sustained economic and political turbulence 2 .

Over recent years, the EU has also displayed a growing appetite to experiment with different funding models - from investigator-led frontier research to largescale consortia. In research-policy circles, this means it increasingly leads by example. The European Research Council (ERC), in particular, has risen with unusual speed into the premier league of global funders since its launch in 2007, and is now seen by others as a template. For example, as part of its post-Brexit planning, the UK government is exploring options for an ERC-like funding mechanism.

The EU institutions have themselves been re-engineered to take this more ambitious role. Late last month, Jean-Eric Paquet, director-general for research and innovation at the European Commission, unveiled a major shake-up of his 1,463-strong directorate. It has been recast to enable more effective cooperation across the commission, in support of goals in four areas: healthy planet; clean planet; people; and prosperity (see go.nature.com/2jadnmg). Kurt Deketelaere, secretary-general of the League of European Research Universities in Leuven, Belgium, told us that there has been "a complete turnaround from the commission as an agency for research funding, to one where it is primarily a research policymaker".

\section{COSMOPOLITAN VALUES}

As historians of science Michael Barany and John Krige observe in the 2019 book How Knowledge Moves, it can seem old-fashioned to focus on transnational science at a time of resurgent nationalism and populism in so many countries ${ }^{3}$. But when others are turning inwards, the framework programmes stand as a beacon for collaboration on an unprecedented scale.

More than 40 countries are involved in the current framework programme,
Horizon 2020. A lively debate is under way about loosening the rules of association to Horizon Europe for an even larger group of countries. The EU needs to uphold this commitment to a cosmopolitan model of research and innovation. Europe's strength is reconciling difference with equality, convergence with plurality (see, for example, ref. 4). This enables it to draw on the best ideas and brightest researchers from across the EU and beyond.

This idea was implied by the last of the 'three Os' - open innovation, open science and open to the world - which were the signature policy of Carlos Moedas, the outgoing EU research commissioner ${ }^{5}$ (see also page 481, 'Rekindle the love affair'). But concrete progress towards the development and expansion of a European Research Area - adopted as an EU goal in 2000 has stalled since 2013, and its future is now under review (see go.nature.com/2w3bw2g; and page 481, 'ERA: no time for complacency'). Brexit has "Europe's further complicated strength is matters, as have calls reconciling from some, such difference Dan Nica, for a narwith equality, $\quad$ Dan Nica, for a narconvergence, approach to research withplurality." and innovation funding.

Pascal Lamy, chair of a high-level expert group tasked with evaluating the future of the framework programmes, made the opposite case in his 2017 review $^{6}$. He urged the EU to "continuously invite the rest of the world to collaborate in research and innovation". On the basis of mutual excellence and reciprocal funding, he wrote, future frameworks could become "the potential nucleus of a global programme”. Similar points are made in a new report to the European Parliament ${ }^{7}$, which argues that remaining open to global talent is in the EU's interests, even if China and the United States retrench from collaboration.

\section{OPENING DOORS}

The two other 'Os' - open innovation and open science - have been a significant focus of Moedas's political energy over the past four years. This has given rise to the European Open Science Cloud, a virtual repository for data produced by Europe's 1.7 million publicly funded researchers. And streams of work are ongoing under the Open Science Policy Platform on issues such as scholarly publishing, rewards and incentives, next-generation metrics and research integrity. These will

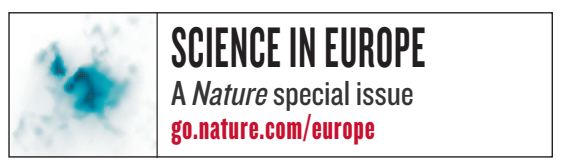

come to fruition in the final design of Horizon Europe, to be unveiled over the next few months.

More dramatic still was the launch of Plan S in September last year by a group of European funders. Although this radical initiative to accelerate the transition to open-access publishing formally emerged from outside the European Commission, its principal architect was Robert-Jan Smits, former director-general of research and innovation, and it secured Moedas's ringing support.

Wider reactions to Plan $S$ have been mixed, with a number of technical and practical challenges still to be ironed out. Outside Europe, many funders are yet to come on board - including the large federal funding agencies in the United States.

But Plan S continues to build momentum, with the National Natural Science Foundation of China (NSFC) and the governments of India and Zambia among its latest recruits. The likelihood is that the plan will become the global framework for open access - making it the most visible example yet of European scientific leadership. As Jean-Claude Burgelman, head of open data policies at the European Commission's Directorate General for Research and Innovation, said to us: "Will people remember the role of the European Commission ten years from now? I don't know. But does this matter? The proof of success is others taking ownership."

\section{GLOBAL EXAMPLE}

Another of Europe's innovations has been to direct funding towards global challenges. Five 'missions' were agreed in March: adapting to climate change; cancer; healthy oceans, seas and coastal and inland waters; climate-neutral and smart cities; and soil health and food.

The move to missions was a Lamy recommendation, further developed by economist Mariana Mazzucato in a 2018 report $^{8}$. The scheme has its critics, particularly those who fear it could lead to reduced support for fundamental research. And debates persist about what constitutes a mission, challenge or goal.

Semantics aside, the commission intends the missions to trigger a bigger shift in how it operates - from siloed policymaking to a more to joined-up approach. "This is not business as usual," Paquet underlined in an April speech at the European University Association's conference in Paris. The overhaul of his directorate is accompanied for the first time by a single research budget across the commission, which will be allocated with input from other directorates and external stakeholders.

Co-creation is a term often used by senior commission officials. Lamy called 
for the next framework to become "the biggest co-created ... programme in the world" . Burgelman emphasizes that co-creation with the scientific community underpins both the new missions and the commission's approach to open science.

It remains to be seen how successful this model is, and how widely it can cast the net in terms of delivering missions with the engagement of the research community, and of wider society. Some, such as the European Alliance for Social Sciences and Humanities, worry that without a bigger role for these fields, the missions are "doomed". Others call for more radical models, involving civil society and citizens in the design of ethical, responsible - and distinctively European - approaches to developments in fields such as artificial intelligence.

Science and innovation have not always been at the forefront of Europe's priorities (see go.nature.com/2jyrvff). But through its emphasis on research that is cosmopolitan, open and missiondirected, the EU is undeniably in the driving seat of global scientific governance. The next European Parliament and European Commission should ensure that research - and its good governance - remains at the top of their agendas for the next five years. This is one arena in which Europe now leads, and others follow. -

James Wilsdon is professor of research policy at the University of Sheffield, UK. Sarah de Rijcke is director of the Centre for Science and Technology Studies at Leiden University, the Netherlands.

e-mails: j.wilsdon@sheffield.ac.uk; s.de.rijcke@cwts.leidenuniv.nl

1. Reillon, V. EU Framework Programmes for Research and Innovation: Evolution and Key Data from FP1 To Horizon 2020 in View of FP9 (European Parliamentary Research Service, 2017).

2. Benner, M. The New Global Politics of Science: Knowledge, Markets and the State (Edward Elgar, 2018).

3. Barany, M. J. \& Krige, J. in How Knowledge Moves (ed. Krige, J.) 412 (Univ. Chicago Press, 2019).

4. Beck, U. \& Grande, E. Cosmopolitan Europe (Polity, 2007).

5. European Commission Directorate-General for Research and Innovation. Europe's

Future: Open Innovation, Open Science, Open to the World. Reflections of the RISE Group (European Commission, 2017).

6. European Commission Directorate-General for Research and Innovation. $L A B-F A B-$ APP: Investing in the European Future We Want (European Commission, 2017).

7. Veugelers, R. \& Baltensperger, M. Europe - The Global Centre for Excellent Research (European Parliament, 2019).

8. Mazzucato, M. Mission-Oriented Research \& Innovation in the European Union (European Commission, 2018).

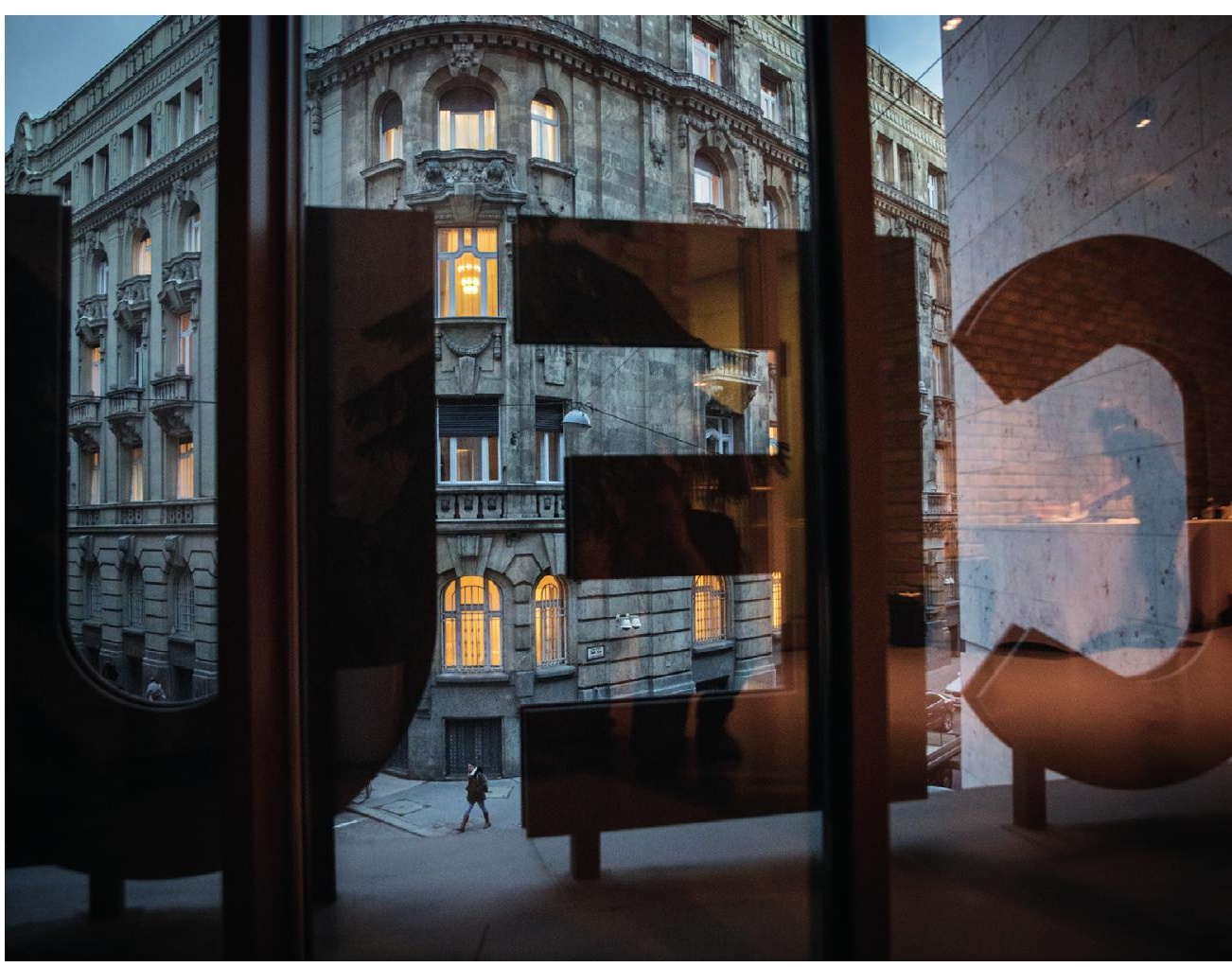

Hungarian politics are forcing a move for the Central European University from Budapest to Vienna.

\title{
Views from a continent in flux
}

\author{
Nature asked nine leading Europeans to pick their top \\ priority for science at this pivotal point. Love, money, \\ and trust got most votes.
}

\section{CARLOS MOEDAS Rekindle the love affair}

European Commissioner, Research, Science and Innovation.

We live in an age of both scientific discovery and scientific denial. The first black-hole images dominated the headlines. At the same time, many people are willing to trust social media more than science. Populist politicians are attacking research, cutting funding and questioning the value of evidence. People seem to have fallen out of love with science. I strongly believe that Europe must lead the fight back - to encourage our societies to do as climate activist Greta Thunberg urges, and "Listen to Science!".
This needs three things in particular.

First, more openness. Science must no longer be hidden from the public or from other scientists. Open science empowers researchers, fosters interdisciplinarity and levels the playing field for less well-heeled institutes. It also reflects fundamental European values of inclusiveness and respect for the individual. It means giving back to scientists the ownership and control of their work, a bit like the way that Europe's General Data Protection Regulation (GDPR) allows citizens to control their data. And like GDPR, Europe is setting the standards in open science that the world will follow.

The recent Plan S is a bold step forward on this front, which the European Commission, along with a growing number of national funders, is committed to implement. This will not be easy, as we need to ensure excellence, academic freedom and innovation in scientific publishing. But we must also start to 